\title{
Computation of Ecological Properties, Flammability Properties and Thermodynamic Properties of Sustainable Refrigerant Dimethylether (RE170) Using Martin Hou Equation of State (MHEOS)
}

\author{
Sharmas Vali Shaik*, Talanki Puttaranga Setty Ashok Babu \\ Department of Mechanical Engineering, National Institute of Technology Karnataka, Surathkal, Mangalore-575025, India
}

Corresponding Author Email: sharmasvali.nitk@gmail.com

https://doi.org/10.18280/ijht.370325

Received: 29 January 2019

Accepted: 1 August 2019

\section{Keywords:}

equation of state, ODP, GWP, RF number, saturated properties, vapour specic volume

\begin{abstract}
The objective of present work is to investigate the thermodynamic properties, ecological properties and flammability properties of a refrigerant Dimethylether (RE170). Ecological properties such as ozone depletion potential (ODP) and global warming potential (GWP) were reported and validated with literature. Flammability properties such as upper flammability limit (UFL), lower flammability limit (LFL) and refrigerant flammability (RF) number were reported and validated with literature. Martin-Hou equation of state (MHEOS) is used while computing the thermodynamic properties of RE170. In this investigation, a MATLAB code was developed in order to compute the properties of RE170 over the wide temperature range about $131.6 \mathrm{~K}$ to $398.15 \mathrm{~K}$ and pressure up to 51.3 bar. The computed thermodynamic properties of RE170 were validated against REFPROP database, since its thermodynamic properties were not available in the existing literature. Therefore, REFRPROP can be considered as a reliable source as that of ASHRAE. Results showed that refrigerant RE170 has zero ODP and very low GWP (equals to one). Similarly RE170 has LFL of 3.34 vol\%, UFL of $25.60 \mathrm{vol} \%$ and RF number of $51.05 \mathrm{~kJ} / \mathrm{g}$. Results of thermodynamic properties of RE170 revealed that the mean absolute deviation (MAD) between computed liquid and vapour phase enthalpy values and REFPROP values was $1.01 \%$ and $0.32 \%$, respectively. Similarly MAD between computed liquid and vapour phase entropy values and REFPROP values was $1.05 \%$ and $0.25 \%$. MAD of saturation pressure was $0.071 \%$. MAD between computed vapour specific volume, liquid density values and REFPROP values was $1.49 \%$ and $0.25 \%$. Overall, computed thermodynamic, ecological and flammability properties of RE170 shows good agreement with literature.
\end{abstract}

\section{INTRODUCTION}

Refrigerant R22 is most widely used in heat pump and air conditioning sectors due to its excellent thermodynamic characteristics. However, R22 has adverse ecological impacts like high ozone depletion potential (ODP) and high global warming potential (GWP) [1]. Hence, Montreal protocol have decided to ban the Hydrochlorofluorocarbon (HCFC) refrigerant R22 completely by the year 2030 [1-3]. Therefore, it is necessary to develop the refrigerants which will possess zero ODP and low GWP. Over the last few years, air conditioning and refrigeration industry focuses on low global warming potential (GWP) refrigerants in order to solve the global warming problem. In this context, many nations are keenly focusing on the development of their own low GWP R22 alternative refrigerants.

To analyze the performance of refrigeration cycle thermodynamic properties of refrigerants are required. Pressure-volume-temperature (PvT) properties of refrigerants are computed from the equation of state. Refrigerant Dimethylether (RE170) is considered as a suitable replacement to R134a [22]. RE170 can also be used as a part component of R22 alternative blends. Therefore, the present study focuses on the development of thermodynamic properties of an ecofriendly refrigerant RE170.

Earlier several studies have been carried out to establish the thermodynamic properties of various refrigerants. Barret and Candau (1992) were computed the thermodynamic properties of refrigerants such as R125 and R143a using Martin-Hou equation of state (MHEOS) [4]. Results showed that data obtained from the equation of state for R143a matches well with the experimental data of refrigerant R143a. De Monte (2002 a) developed the theoretical thermodynamic property modeling of two R22 alternative refrigerants namely R410A and R407C using MHEOS [5]. De Monte (2002 b) considered the effect of temperature along with the predominant effect of pressure, while establishing the thermodynamic properties of two R22 alternatives such as R410A and R407C [6].

Investigation on estimation of thermodynamic properties of refrigerant R1234yf was done by using various cubic equation of state models [7]. The properties obtained from these models were validated against most reliable NIST-REFPROP data base. Investigation on prediction of liquid density and vapour pressure of refrigerant RE170 (Dimethylether) was done based on artificial neural networks using back-propagation algorithm [8]. Prediction of above properties exhibited good agreement with the experimental data. Experimental investigation on an ice cream refrigerator was done using refrigerant R404A and its alternative refrigerant R290/RE170 [9]. Test results showed that time taken to form ice cream using the refrigerant mixture R290/RE170 (65/35 by mass \%) was less compared to R404A and also its COP was better compared to R404A. Simulation studies were done with refrigerant mixtures like R744/RE170 and R1234ze(E)/R32 in order to exhibit possible ways to use these refrigerants as next generation refrigerants in the heat pump and refrigeration sectors [10]. 
Applicability of Martin-Hou equation of state (MHEOS) was discussed in this section. Experimental studies were conducted using a constant volume apparatus in order to measure the vapor phase PvT Properties of refrigerant $\mathrm{R} 1225 y \mathrm{y}(\mathrm{Z})$ over temperature ranges from (263 to 368 ) $\mathrm{K}$ and pressure ranges from (135 to 777) $\mathrm{kPa}$ [11]. In this study, the experimental vapour phase PvT properties of $\mathrm{R} 1225 \mathrm{ye}(\mathrm{Z})$ were compared with MHEOS. Results showed that the deviations between computed values of PvT using MHEOS and experimental values were $(-0.54$ to 0.52$) \%$ with an average absolute deviation (AAD) of 0.170. Experimental tests were performed using isochoric apparatus in order to measure the vapor phase PvT Properties of refrigerant R1243zf over temperature ranges from (268 to 368) K and pressure ranges from (220 to 910$) \mathrm{kPa}$ [12]. In this research work, the experimental vapour phase PvT Properties of R1243zf were compared with MHEOS. Results revealed that the deviations between computed values of PvT using MHEOS and experimental values were (-0.65 to 1.27$) \%$ with an average absolute deviation (AAD) of 0.305 .

Experimental investigations were carried out by using a constant volume apparatus in order to measure the vapor phase PvT Properties of refrigerant R1234ze(E) over temperature ranges from (243 to 373 ) $\mathrm{K}$ and pressure ranges from ( 57 to 1024) $\mathrm{kPa}$ [13]. In this study, the experimental vapour phase PvT Properties of R1234ze(E) were compared with a MHEOS. Results showed that the deviations between computed values of PvT using MHEOS and experimental values were (-0.35 to $0.38) \%$ with an average absolute deviation (AAD) of 0.198 . Experimental tests were done by using an isochoric apparatus in order to measure the vapor phase PvT Properties of refrigerant R1234yf over temperature ranges from (243 to $373) \mathrm{K}$ and pressure ranges from (84 to 3716$) \mathrm{kPa}$ [14]. In this study, the experimental vapour phase PvT Properties of R1234yf were compared with a MHEOS. Results exhibited that the deviations between computed values of PvT using MHEOS and experimental values were (-1.18 to 1.27$) \%$ with an average absolute deviation (AAD) of 0.44 .

Dong et al., proposed an empirical correlation to conveniently compute parameter B4 of the Martin-Hou equation of state (MHOS) at various temperatures by relating $\mathrm{B} 4(\mathrm{~T})$ with B4(0.7) (B4 at reduced temperature=0.7) after analyzing B4(T) of more than 200 compounds [15]. In this study, the accuracy of MHEOS to compute volume of various refrigerants by using the proposed equation was verified by comparing the calculated data with literature data. An empirical correlation used to compute B4 is given below.

$$
\begin{gathered}
\ln \left(\mathrm{R}_{\mathrm{a}}\right)=-0.40379 \times 10^{-2} \times\left(\mathrm{V}_{\mathrm{c}}-\mathrm{b}\right) \times\left(\mathrm{T}_{\mathrm{r}}-0.7\right)+ \\
2.4189 \times\left(\mathrm{T}_{\mathrm{r}}-0.7\right)^{2} \\
\mathrm{R}_{\mathrm{a}}=\frac{\mathrm{B}_{4}(\mathrm{~T})}{\mathrm{B}_{4}(0.7)} \\
\mathrm{T}_{\mathrm{r}}=\frac{\mathrm{T}}{\mathrm{T}_{\mathrm{c}}}
\end{gathered}
$$

Results showed that the proposed equation improves the accuracy in the results of properties obtained from the MHEOS and also significantly decreases the computational time to determine parameter B4, which could enhance the application of the MHEOS in engineering calculations. In the present work, correlation proposed by the Dong et al, in order to compute B4 parameter of MHEOS was used.
From the above literature, it is evident that MHEOS can be conveniently used in mechanical engineering, chemical engineering and refrigeration technology design. Therefore, MHEOS was used in the present study, in order to calculate refrigerant RE170 (Dimethylether) thermodynamic properties. The methodology followed to calculate various refrigerant thermodynamic properties is explained in the methodology section.

Thermodynamic properties of refrigerant RE170 such as saturation vapour pressure, liquid density, specific volume, enthalpy and entropy (both in the saturated liquid and vapour state) were not available in the ASHRAE data hand book as well as in the related literature. Hence, a significant research gap is found in the present study to develop the refrigerant RE170 thermodynamic properties using MHEOS. Therefore, the present study emphases on the thermodynamic property modeling and development of properties of a refrigerant RE170 (Dimethylether) using MHEOS. Apart from thermodynamic properties, computation of ecological properties and flammability properties are also carried out in this study.

\section{COMPUTATION OF ECOLOGICAL PROPERTIES OF REFRIGERANT RE170}

Commonly, environmental impact of several refrigerants is investigated by computing their ecological properties such as ODP and GWP. In order to protect ozone layer and also to decrease the greenhouse effect of atmospheric environment, alternative refrigerants not only desire zero ODP but also it desires lower value of GWP. Correlations used to compute ODP and GWP of several refrigerants were taken from related literature and they are given below [18-21].

$$
\mathrm{ODP}_{\mathrm{i}}=\left(\alpha \mathrm{n}_{\mathrm{Br}, \mathrm{i}}+\mathrm{n}_{\mathrm{Cl}, \mathrm{i}}\right) \times \frac{\mathrm{f}_{\mathrm{i}}}{\mathrm{f}_{\mathrm{CFC}-11}} \times \frac{\tau_{\mathrm{i}}}{\tau_{\mathrm{CFC}-11}} \times \frac{\mathrm{MW}_{\mathrm{CFC}-11}}{\mathrm{MW}_{\mathrm{i}}} \times \frac{1}{3}
$$

where, $f$ is the halogen fractional release factor, $\alpha$ is the relative effectiveness of bromine when compared with chlorine for ozone depletion, $\tau$ is the overall lifespan, MW is the molecular weight, and $\mathrm{n}_{\mathrm{Cl}}\left(\mathrm{n}_{\mathrm{Br}}\right)$ is the number of chlorine (bromine) atoms present in the refrigerant. CFC-11 subscripts designate quantities for $\mathrm{CFC}-11$, while i subscripts indicate quantities relating to the refrigerant for which the ODP is required.

$$
G W P=\frac{\int_{0}^{t}\left(F_{x} e^{\frac{-t}{t_{x}}} d t\right)}{\int_{0}^{t}\left(F_{\mathrm{CO}_{2}} R_{t} d t\right)}
$$

where, $F_{x}$ is the radiative forcing per unit mass of species $x, t$ is the time horizon considered, $\mathrm{F}_{\mathrm{CO}_{2}}$ is the radiative forcing of $\mathrm{CO}_{2}, \mathrm{R}(\mathrm{t})$ is the response function that defines the deterioration of an instantaneous pulse of $\mathrm{C}_{\mathrm{O} 2}$ and $\mathrm{t}_{\mathrm{x}}$ is the atmospheric life cycle.

By using Eqns. (4) and (5), the values of ODP and GWP for refrigerant RE170 were computed and they are compared with literature results $[16,22]$. Comparison of computed ecological properties (ODP and GWP) of refrigerant RE170 with results from related literature is given in Table 1. 
Table 1. Comparison of computed ODP and GWP values of refrigerant RE170 with literature results $[16,22]$

\begin{tabular}{ccccc}
\hline S.no & $\begin{array}{c}\text { Ecological } \\
\text { properties }\end{array}$ & $\begin{array}{c}\text { Computed } \\
\text { values for } \\
\text { RE170 }\end{array}$ & $\begin{array}{c}\text { Literature } \\
\text { values for } \\
\text { RE170 }\end{array}$ & $\begin{array}{c}\text { Deviation } \\
(\%)\end{array}$ \\
\hline 1 & ODP & 0 & 0 & 0 \\
2 & $\begin{array}{c}\text { GWP }(100 \\
\text { years })\end{array}$ & 1.012 & 1 & -1.20 \\
\hline
\end{tabular}

From Table 1, it is observed that the computed ODP and GWP values of refrigerant RE170 shows excellent agreement with that of literature values. The deviation of computed values of ecological properties of RE170 when compared with literature values was within $1.25 \%$. Therefore, the empirical correlations which were used to compute ecological properties can be considered as reliable.

The basic physical properties of refrigerant Dimethylether (RE170) were taken from related literature and they are presented in Table 2 [17].

From Table 1, it is also observed that refrigerant RE170 has zero ODP and negligible GWP. Therefore, refrigerant RE170 can be considered as an environmental friendly refrigerant. RE170 can be used as one of the mixing components with other Hydrofluorocarbons (HFCs) in order to reduce the GWP of mixture and also to improve the performance of the mixture. In this context, Shaik and Babu (2017) computed the theoretical performance of VCR cycle using four ternary refrigerant mixtures consists of R32, R134a, R290, R1270 and $\mathrm{RE} 170$ as replacements to $\mathrm{R} 22$, operating at $\mathrm{T}_{\mathrm{e}}=7.2{ }^{\circ} \mathrm{C}$ and $\mathrm{T}_{\mathrm{k}}=54.4{ }^{\circ} \mathrm{C}$ by considering subcooling and superheating as $5{ }^{\circ} \mathrm{C}$ [23]. Authors were neglected the various losses occurred in the cycle, while doing the performance study of various considered blends. The performance results of various blend studied were presented in the Table 3.

Table 2. Physical properties of refrigerant Dimethylether (RE170)

\begin{tabular}{ccccc}
\hline Refrigerant & $\begin{array}{c}\mathbf{M W} \\
(\mathbf{k g} / \mathbf{k m o l})\end{array}$ & $\begin{array}{c}\mathbf{B P} \\
\left({ }^{\mathbf{0}} \mathbf{C}\right)\end{array}$ & $\begin{array}{c}\mathbf{T}_{\mathbf{c}} \\
(\mathbf{K})\end{array}$ & $\begin{array}{c}\mathbf{P}_{\mathbf{c}} \\
(\mathbf{M P a})\end{array}$ \\
\hline RE170 & 46.06 & -24.78 & 400.38 & 5.336 \\
\hline
\end{tabular}

Table 3. Performance results of four ternary mixtures [23]

\begin{tabular}{|c|c|c|c|c|c|c|c|}
\hline Refrigerants & $\begin{array}{c}\text { Composition } \\
(\text { mass \%) }\end{array}$ & $\begin{array}{c}\mathrm{CE} \\
(\mathrm{kJ} / \mathbf{k g})\end{array}$ & $\begin{array}{c}W_{c} \\
(\mathbf{k J} / \mathbf{k g})\end{array}$ & COP & $\begin{array}{l}\text { Change in } \\
\text { COP }(\%)\end{array}$ & ODP & $\begin{array}{c}\text { GWP } \\
\text { (100 years) }\end{array}$ \\
\hline $\mathrm{R} 22$ & Pure fluid & 139.944 & 34.958 & 4.003 & 0 & 0.055 & 1760 \\
\hline TRM10 (R32/R290/R134a) & $17.5 / 2.5 / 80$ & 151.088 & 43.949 & 3.437 & -14.13 & 0 & 1159 \\
\hline TRM20 (R32/R290/R134a) & $25 / 7.5 / 67.5$ & 164.048 & 48.397 & 3.389 & -15.33 & 0 & 1047 \\
\hline TRM30 (R134a/RE170/R1270) & $55 / 7.5 / 37.5$ & 216.243 & 51.274 & 4.217 & 5.34 & 0 & 716 \\
\hline TRM40 (R134a/ RE170/R290) & $55 / 7.5 / 37.5$ & 200.528 & 49.206 & 4.075 & 1.79 & 0 & 716 \\
\hline R407C (R32/R125/R134a) & $23 / 25 / 52$ & 137.816 & 42.645 & 3.231 & -19.28 & 0 & 1624 \\
\hline
\end{tabular}

From Table 3, it is noticed that the performance of ternary refrigerant mixture TRM30 (R134a/RE170/R1270 55/7.5/37.5 composition mass \%) was $5.35 \%$ higher than that of R22. Apart from refrigerant TRM30, the refrigerant mixture TRM40 also has considerable increase in COP compared to R22. From this thermodynamic performance results, it is evident that mixing the RE170 with other refrigerants (R134a, R290 and R1270) enhances the performance of the system.

\section{COMPUTATION OF FLAMMABILITY PROPERTIES OF REFRIGERANT RE170}

Flammability gives the range of fuel concentration limits with in which refrigerants can burn or ignite. Therefore, investigation on flammability of refrigerants is vital while developing new alternative refrigerants from the view point of safety and handling the refrigerants. In this study, flammability properties such as upper flammability limit, lower flammability limit and refrigerant flammability number are computed for the refrigerant RE170.

In this work, formulas used in order to compute flammability limits (upper and lower) of RE170 were taken from literature and they are expressed below [24-25].

$$
\begin{gathered}
\mathrm{UFL}=3.9 \mathrm{C}_{\text {st }} \\
\mathrm{LFL}=0.512 \mathrm{C}_{\text {st }}
\end{gathered}
$$

where, $\mathrm{C}_{\mathrm{st}}=$ stoichiometric oxygen concentration. In order to compute $\mathrm{C}_{\mathrm{st}}$ of any given refrigerant, the following formula can be used [26].

$$
\mathrm{C}_{\mathrm{st}}=\frac{83.8 \%}{4 \mathrm{C}+4 \mathrm{~S}+\mathrm{H}-\mathrm{X}-2 \mathrm{O}+0.84} \operatorname{vol} \%
$$

where, C, S, H, X and $\mathrm{O}$ are number of carbons, sulfur, hydrogen, halogen and oxygen atoms presented in the given refrigerant, respectively.

By using equations (6-8), values of flammability limits of refrigerant RE170 are calculated as $3.34 \mathrm{vol} \%$ and $25.60 \mathrm{vol} \%$, respectively.

In this study, in order to compute refrigerant flammability number of RE170, correlation proposed by the S Kondo et al. (2002) was used and it is expressed below [27].

$$
\text { RF number }=\left\{\left(\frac{\mathrm{UFL}}{\mathrm{LFL}}\right)^{0.5}-1\right\} \times \frac{\mathrm{HOC}}{\mathrm{MW}}
$$

The value of heat of combustion (HOC) for RE170 was taken from literature and it is given as $(\mathrm{HOC})_{\mathrm{RE} 170}=1328$ $\mathrm{kJ} / \mathrm{mol}$ [27]. By using equation (9), the value of RF number of refrigerant RE170 is calculated as $51.05 \mathrm{~kJ} / \mathrm{g}$. Flammability properties (UFL, UFL and RF number) obtained from the equations (6-9) for the refrigerant RE170 were compared with literature results and it is presented in Table 4 [27].

From Table 4, it is noticed that the computed flammability properties of RE170 exhibits satisfactory agreement with that of literature results and deviation is within $2.5 \%$. Therefore, correlations which were used to compute the flammability properties of RE170 can be treated as reliable. S Kondo et al., (2002) categorized the refrigerants into different flammability categories based on their RF number [27]. For example, 
refrigerants having RF number range $30-150 \mathrm{~kJ} / \mathrm{g}$ were classified the refrigerants into highly flammable group (ASHRAE A3). On the other hand, ASHRAE standard 34, categorized the refrigerant RE170 into highly flammable group (ASHRAE A3) [28].

Table 4. Comparison of flammability properties of refrigerant RE170 with literature results [27]

\begin{tabular}{ccccc}
\hline S.no & $\begin{array}{c}\text { Flammablity } \\
\text { properties of } \\
\text { RE170 }\end{array}$ & $\begin{array}{c}\text { Computed } \\
\text { values for } \\
\text { RE170 }\end{array}$ & $\begin{array}{c}\text { Literature } \\
\text { values for } \\
\text { RE170 }\end{array}$ & $\begin{array}{c}\text { Deviation } \\
(\%)\end{array}$ \\
\hline 1 & LFL (vol\%) & 3.34 & 3.40 & 1.76 \\
2 & UFL (vol\%) & 25.60 & 27.0 & 5.18 \\
3 & RF number & 51.05 & 52.41 & 2.59 \\
& $(\mathrm{~kJ} / \mathrm{g})$ & & & \\
\hline
\end{tabular}

From Table 4, it is also noticed that, refrigerant RE170 can be considered as highly flammable refrigerant, since its refrigerant flammability number $51.05 \mathrm{~kJ} / \mathrm{g}$ falls in the range of $30-150 \mathrm{~kJ} / \mathrm{g}$. From the RF number and ASHRAE standard 34 , it is evident that the refrigerant RE170 is classified as highly flammable refrigerant and also refrigerant flammability number exhibits satisfactory agreement with that of ASHRAE standard 34. Therefore, RF number can be treated as reliable source for categorizing the refrigerants into different flammability groups.

\section{METHODOLOGY TO DEVELOP PROPERTIES OF PURE REFRIGERANTS}

\subsection{Methodology to establish thermodynamic properties of refrigerant RE170 (Dimethylether)}

Methodology used to calculate refrigerant thermodynamic properties is discussed in this section and it is given below. Pressure-Enthalpy (P-h) chart used, while estimating the thermodynamic properties of pure refrigerant is shown in Figure 1 [29].

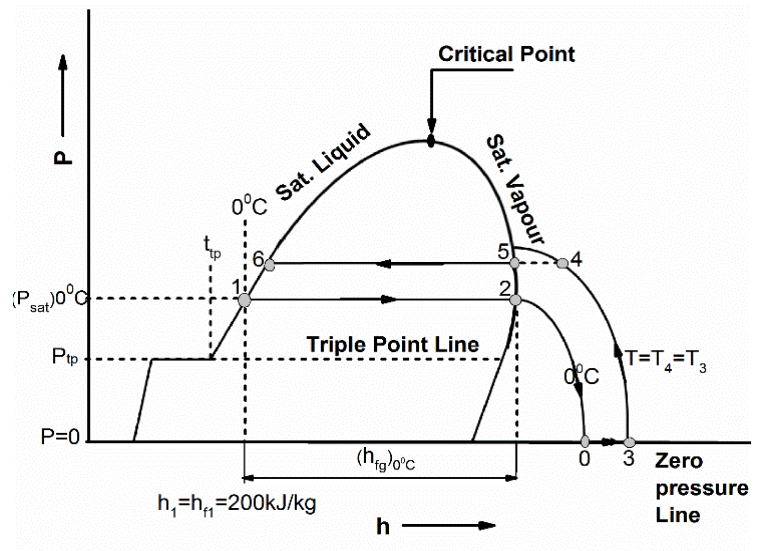

Figure 1. Pressure-Enthalpy chart used for estimation of pure refrigerant properties

\subsection{Saturation vapour pressure}

Initially, saturation vapour pressure of refrigerant is computed. The relation between saturation pressure $\left(\mathrm{P}_{\text {sat }}\right)$ and saturation temperature $\left(\mathrm{T}_{\mathrm{sat}}\right)$ is stated by Wagner and corresponding saturation vapour pressure equation is given below [30].

$$
\ln \left(\frac{\mathrm{P}_{\mathrm{sat}}}{\mathrm{P}_{\mathrm{c}}}\right)=\left(\frac{1}{1-\mathrm{x}}\right)\left[\mathrm{A}_{1} \mathrm{x}+\mathrm{B}_{1} \mathrm{x}^{1.5}+\mathrm{C}_{1} \mathrm{x}^{2.5}+\mathrm{D}_{1} \mathrm{x}^{5}\right]
$$

where, $\mathrm{x}=1-\left(\frac{\mathrm{T}}{\mathrm{T}_{\mathrm{c}}}\right) ; \mathrm{A}_{1}, \mathrm{~B}_{1}, \mathrm{C}_{1}$ and $\mathrm{D}_{1}$ are constants for a specific refrigerant and the values of above constants for Wagner equation are presented in the related research article for several different refrigerants [30]. Constants of saturation vapour pressure for refrigerant RE170 is given in Table 5

Table 5. Constants of RE170 for equation (10)

\begin{tabular}{cccc}
\hline $\mathbf{A}_{\mathbf{1}}$ & $\mathbf{B}_{\mathbf{1}}$ & $\mathbf{C}_{\mathbf{1}}$ & $\mathbf{D}_{\mathbf{1}}$ \\
\hline-6.9798 & 1.523 & -1.6409 & -2.7943 \\
\hline
\end{tabular}

\subsection{Liquid phase density}

Next, refrigerant RE170 liquid density is computed. In the present study, Reid et al, equation was used to calculate the RE170 liquid density [31-32].

$$
\begin{gathered}
\rho_{\mathrm{r}}=\frac{\rho}{\rho_{\mathrm{C}}}=1+0.85 \times\left(1-\mathrm{T}_{\mathrm{r}}\right) \\
+(1.6916+0.984 \times \omega) \times\left(1-\mathrm{T}_{\mathrm{r}}\right)^{1 / 3}
\end{gathered}
$$

where, $\omega$ is acentric factor; $\mathrm{T}_{\mathrm{r}}=\mathrm{T} / \mathrm{T}_{\mathrm{c}}, \omega, \rho_{\mathrm{c}}$ and $\mathrm{T}_{\mathrm{c}}$ are constants for a specific refrigerant and values of these constants for several different refrigerants are available in the related literature [33]. Constansts of Reid et al, density correlation for refrigerant RE170 are listed in Table 6.

Table 6. Constants of RE170 for equation (11)

\begin{tabular}{ccc}
\hline $\boldsymbol{\omega}$ & $\boldsymbol{\rho}_{\mathbf{c}}\left(\mathbf{k g} / \mathbf{m}^{\mathbf{3}}\right)$ & $\mathbf{T}_{\mathbf{c}}(\mathbf{K})$ \\
\hline 0.196 & 273.65 & 400.38 \\
\hline
\end{tabular}

\subsection{Specific volume of vapour}

Next, vapour specific volume of refrigerant RE170 is calculated. In the present research work, vapour specific volume of refrigerant RE170 was computed by using MHEOS $[15,34]$.

Table 7. Dimensionless coefficients of refrigerant RE170 for equation (12)

\begin{tabular}{cc}
\hline Dimensionless coefficients of RE170 & Values \\
\hline $\mathrm{A}_{2}$ & -498.4594 \\
$\mathrm{~A}_{3}$ & 2.0780 \\
$\mathrm{~A}_{4}$ & -0.0015 \\
$\mathrm{~B}_{2}$ & 0.3933 \\
$\mathrm{~B}_{3}$ & -0.0029 \\
$\mathrm{~B}_{5}$ & $2.0087 \times 10^{-9}$ \\
$\mathrm{C}_{2}$ & $-1.2235 \times 10^{4}$ \\
$\mathrm{C}_{3}$ & 35.4344 \\
$\mathrm{~b}$ & $9.2042 \times 10^{-4}$ \\
\hline \\
$\mathrm{P}=\frac{\mathrm{RT}}{\mathrm{V}-\mathrm{b}}+\frac{\mathrm{A}_{2}+\mathrm{B}_{2} \mathrm{~T}+\mathrm{C}_{2} \mathrm{e}^{\frac{-5.475 \mathrm{~T}}{\mathrm{~T}_{\mathrm{C}}}}+\frac{\mathrm{A}_{3}+\mathrm{B}_{3} \mathrm{~T}+\mathrm{C}_{3} \mathrm{e}^{\frac{-5.475 \mathrm{~T}}{\mathrm{~T}_{\mathrm{C}}}}}{(\mathrm{V}-\mathrm{b})^{2}}}{(\mathrm{~V}-\mathrm{b})^{3}}$ \\
\multicolumn{2}{c}{}
\end{tabular}

where, $\mathrm{A}_{2}, \mathrm{~A}_{3}, \mathrm{~A}_{4}, \mathrm{~B}_{2}, \mathrm{~B}_{3}, \mathrm{~B}_{5}, \mathrm{C}_{2}, \mathrm{C}_{3}$ and $\mathrm{b}$ are dimensionless coefficients of MHEOS for different refrigerants. Method 
followed to calculate above coefficients is described in the related literature [15, 34]. By solving the equation (12), dimensionless coefficients of MHEOS were obtained for given refrigerant RE170 and they are presented in Table 7.

\subsection{Enthalpy of vapourization}

Enthalpy of vapourization of given refrigerant is computed. Clausius-Clapeyron equation was used in this research work, in order to calculate the enthalpy of vapourization of given refrigerant RE170 [29].

$$
\frac{\mathrm{dP}_{\mathrm{sat}}}{\mathrm{dT}}=\frac{\mathrm{h}_{\mathrm{fg}}}{\mathrm{T} \times \mathrm{V}_{\mathrm{fg}}}=\frac{\mathrm{h}_{\mathrm{fg}}}{\mathrm{T} \times\left(\mathrm{V}_{\mathrm{g}}-\mathrm{V}_{\mathrm{f}}\right)}
$$

\subsection{Departure method}

Departure method is followed, in order to calculate the entropy and enthalpy of different refrigerants [29, 33]. Enthalpy and entropy properties (both liquid and vapour phase) of given refrigerant RE170 is computed using departure method. Generally, the reference state of entropy and enthalpy is fixed, while computing properties. İn refrigerants case, the reference state chosen is that of saturated liquid at $0{ }^{\circ} \mathrm{C}$. Entropy and enthalpy values allocated to the reference state of saturated liquid at $0{ }^{\circ} \mathrm{C}$ are usually $S_{1}=S_{\mathrm{f} 1}=1.0 \mathrm{~kJ} / \mathrm{kg} \mathrm{K}$ and $\mathrm{h}_{1}=\mathrm{h}_{\mathrm{f} 1}=200 \mathrm{~kJ} / \mathrm{kg}$, respectively $[29,33]$. While comparing the computed properties of RE170 with REFPROP, the same above reference state was used in the NIST REFPROP and therefore validation of computed properties against REFPROP can be considered as reliable.

The importance of departure method is, to calculate the entropy and enthalpy at different state points as shown in Figure 1. For example, to calculate enthalpy at point 3, enthalpy departure method was applied and the corresponding departure function $\left(h_{3}-h_{2}\right)$ is given as follows.

$$
\begin{array}{r}
\mathrm{h}_{3}-\mathrm{h}_{2}=\left(\mathrm{U}_{3}-\mathrm{U}_{2}\right)+\left(\mathrm{P}_{3} \mathrm{~V}_{3}-\mathrm{P}_{2} \mathrm{~V}_{2}\right) \\
\mathrm{U}_{3}-\mathrm{U}_{2}=\int_{2}^{3}\left[\mathrm{~T}\left[\frac{\partial \mathrm{P}}{\partial \mathrm{T}}\right]_{\mathrm{V}}-\mathrm{P}\right] \mathrm{dV}
\end{array}
$$

By solving equations (14) and (15), the $h_{3}$ value can be calculated. In order to compute the enthalpy $\mathrm{h}_{4}$ at point 4 , ideal gas heat capacity equation and difference in enthalpy term $\left(\mathrm{h}_{4-}\right.$ $\mathrm{h}_{3}$ ) can be used and it is given below.

$$
\mathrm{h}_{4}-\mathrm{h}_{3}=\int_{3}^{4} \mathrm{C}_{\mathrm{P} 0} \mathrm{dT}
$$

In this work, ideal gas heat capacity $\left(\mathrm{C}_{\mathrm{P} 0}\right)$ equation was taken from related article and it is presented below [33].

$$
\mathrm{C}_{\mathrm{P} 0}=\mathrm{F}_{0}+\mathrm{F}_{1} \mathrm{~T}+\mathrm{F}_{2} \mathrm{~T}^{2}+\mathrm{F}_{3} \mathrm{~T}^{3}+\mathrm{F}_{4} \mathrm{~T}^{4}
$$

where, $F_{0}, F_{1}, F_{2}, F_{3}$ and $F_{4}$ are constants for a specific refrigerant and values of these constants for several different refrigerants are available in related article [33]. Constants of ideal gas heat capacity for RE170 are presented in Table 8 .

Table 8. Constants of RE170 for equation (17)

\begin{tabular}{ccccc}
\hline $\mathbf{F}_{\mathbf{0}}$ & $\mathbf{F}_{\mathbf{1}}$ & $\mathbf{F}_{\mathbf{2}}$ & $\mathbf{F}_{\mathbf{3}}$ & $\mathbf{F}_{\mathbf{4}}$ \\
\hline 4.361 & 6.070 & 2.899 & -3.581 & 1.282 \\
& $\mathrm{x} 10^{-3}$ & $\mathrm{x} 10^{-5}$ & $\mathrm{x} 10^{-8}$ & $\mathrm{x} 10^{-11}$ \\
\hline
\end{tabular}

In order to find enthalpy $\mathrm{h}_{5}$, once again enthalpy departure method was applied in between the state points 4 and 5. And Corresponding enthalpy departure term $\left(\mathrm{h}_{5}-\mathrm{h}_{4}\right)$ is given below.

$$
\begin{gathered}
\mathrm{h}_{5}-\mathrm{h}_{4}=\left(\mathrm{U}_{5}-\mathrm{U}_{4}\right)+\left(\mathrm{P}_{5} \mathrm{~V}_{5}-\mathrm{P}_{4} \mathrm{~V}_{4}\right) \\
\mathrm{U}_{5}-\mathrm{U}_{4}=\int_{4}^{5}\left[\mathrm{~T}\left[\frac{\partial \mathrm{P}}{\partial \mathrm{T}}\right]_{\mathrm{V}}-\mathrm{P}\right] \mathrm{dV}
\end{gathered}
$$

By solving Eqns. (18) and (19), the $\mathrm{h}_{5}$ value can be calculated. On the other hand, enthalpy of saturated liquid at state point 6 can be calculated by using the following formulas.

$$
\begin{aligned}
& h_{5}-h_{6}=h_{f g} \\
& h_{6}=h_{5}-h_{f g}
\end{aligned}
$$

where, $h_{f g}$ can be computed using Clasius-Clayperon equation at a given temperature.

\subsection{Liquid entropy}

The liquid entropy of given refrigerant is determined. In order to calculate refrigerant thermodynamic properties (entropy and enthalpy) at any given temperature and pressure, the departure method was used, and the corresponding entropy of saturated liquid and enthalpy of saturated liquid was computed with the help of Clausius-Clapeyron equation. Entropy of saturated liquid for any particular refrigerant can be computed by using equations (22) and (23).

$$
\begin{aligned}
& S_{f g}=S_{g}-S_{f} \\
& S_{f}=S_{g}-S_{f g}
\end{aligned}
$$

\subsection{Vapour entropy}

Vapour entropy of any particular refrigerant can be calculated using Eqns. (24) and (25).

$$
\begin{aligned}
& S_{f g}=\frac{h_{f g}}{T_{s a t}} \\
& S_{g}=\frac{h_{g}}{T_{\text {sat }}}
\end{aligned}
$$

By using the above methodology, refrigerant RE170 thermodynamic properties were computed over wide temperature range from about $131.6 \mathrm{~K}$ to $398.15 \mathrm{~K}$ and pressure up to $51.3 \mathrm{bar}$.

\subsection{Validation of results based on literature}

In the present study, a MATLAB program was developed to compute the thermodynamic properties of refrigerant RE170 using MHEOS and various related correlations. The computed thermodynamic properties of RE170 have been validated with NIST-REFPROP data base, since its properties are not presented in the literature and also in the ASHRAE hand book [16]. Hence, REFRPROP can be considered as reliable source as that of ASHRAE data hand book [17]. The validation of thermodynamic properties of RE170 with REFPROP is shown in Table 9 [17].

From Table 9, it is observed that the deviation between computed values of RE170 using MHEOS and NIST 
REFPROP 9.1 values of RE170 was within $1.45 \%$ for the given AHRI operating conditions. Hence, the methodology used to establish thermodynamic properties of RE170 can be considered as reliable and thus it can be employed for the estimation of thermodynamic properties of any given pure refrigerant. Generally, theoretical thermodynamic performance of air conditioners was evaluated at AHRI conditions.

Table 9. Validation of computed thermodynamic properties of refrigerant RE170 with NIST REFPROP 9.1 at AHRI conditions $\left(\mathrm{T}_{\mathrm{e}}=7.2^{\circ} \mathrm{C}\right.$ and $\left.\mathrm{T}_{\mathrm{k}}=54.4^{\circ} \mathrm{C}\right)$

\begin{tabular}{|c|c|c|c|c|c|c|}
\hline $\begin{array}{c}\text { Thermodynamic } \\
\text { properties }\end{array}$ & $\begin{array}{c}\text { REFPROP } \\
\text { Properties for } \\
\text { RE170 } \\
\text { at } \mathrm{T}_{\mathrm{e}}=7.2^{\circ} \mathrm{C} \\
\end{array}$ & $\begin{array}{c}\text { Computed } \\
\text { Properties for } \\
\text { RE170 } \\
\text { at } \mathrm{T}_{\mathrm{e}}=7.2^{\circ} \mathrm{C} \\
\end{array}$ & $\begin{array}{l}\text { Deviation } \\
(\%)\end{array}$ & $\begin{array}{c}\text { REFPROP } \\
\text { Properties for } \\
\text { RE170 } \\
\text { at } \mathbf{T}_{\mathrm{k}}=\mathbf{5 4 . 4}{ }^{\circ} \mathrm{C} \\
\end{array}$ & $\begin{array}{c}\text { Computed } \\
\text { Properties for } \\
\text { RE170 } \\
\text { at } \mathbf{T}_{\mathrm{k}}=54.4^{\circ} \mathrm{C}\end{array}$ & $\begin{array}{l}\text { Deviation } \\
(\%)\end{array}$ \\
\hline $\mathrm{P}_{\text {sat }}(\mathrm{MPa})$ & 0.34073 & 0.34208 & -0.39 & 1.2652 & 1.2732 & -0.63 \\
\hline$\rho_{\mathrm{f}}\left(\mathrm{kg} / \mathrm{m}^{3}\right)$ & 689.24 & 690.45 & -0.17 & 610.42 & 609.76 & 0.1 \\
\hline $\mathrm{V}_{\mathrm{g}}\left(\mathrm{m}^{3} / \mathrm{kg}\right)$ & 0.13627 & 0.13579 & 0.35 & 0.0375 & 0.03724 & 0.7 \\
\hline $\mathrm{h}_{\mathrm{f}}(\mathrm{kJ} / \mathrm{kg})$ & 216.85 & 216.6 & 0.11 & 333.46 & 328.92 & 1.36 \\
\hline $\mathrm{h}_{\mathrm{g}}(\mathrm{kJ} / \mathrm{kg})$ & 642.38 & 639.97 & 0.37 & 685.15 & 680.99 & 0.6 \\
\hline $\mathrm{Sf}(\mathrm{kJ} / \mathrm{kg} \mathrm{K})$ & 1.0605 & 1.0595 & 0.09 & 1.4398 & 1.4267 & 0.91 \\
\hline $\mathrm{sg}(\mathrm{kJ} / \mathrm{kg} \mathrm{K})$ & 2.5783 & 2.5699 & 0.32 & 2.5142 & 2.5006 & 0.54 \\
\hline
\end{tabular}

\subsection{Thermodynamic analysis of refrigerant RE170 using properties obtained from MHEOS}

Commonly, thermodynamic properties of refrigerants are necessary in order to compute thermodynamic performance of any given refrigerants. Therefore, thermodynamic properties obtained from MHEOS for RE170 are used in the present study, to evaluate the performance parameters of given refrigerant RE170.

Theoretical thermodynamic analysis of given refrigerant RE170 was conducted based on standard VCR cycle. The P-h chart of standard VCR cycle is shown in Figure 2. The operating conditions considered, while doing thermodynamic analysis of refrigerant RE170 were taken from literature and they are expressed as $\mathrm{T}_{\mathrm{k}}=50{ }^{\circ} \mathrm{C}, \mathrm{T}_{\mathrm{e}}=-10{ }^{\circ} \mathrm{C}, \Delta T_{\text {sub }}=5{ }^{\circ} \mathrm{C}$ and $\Delta T_{\text {sup }}=10^{\circ} \mathrm{C}$, respectively [22]. In the present investigation, MATLAB program was written, to compute the thermodynamic performance parameters of refrigerant RE170. Thermodynamic properties, operating conditions and various formulas were included in the MATLAB program in order to obtain the performance results.

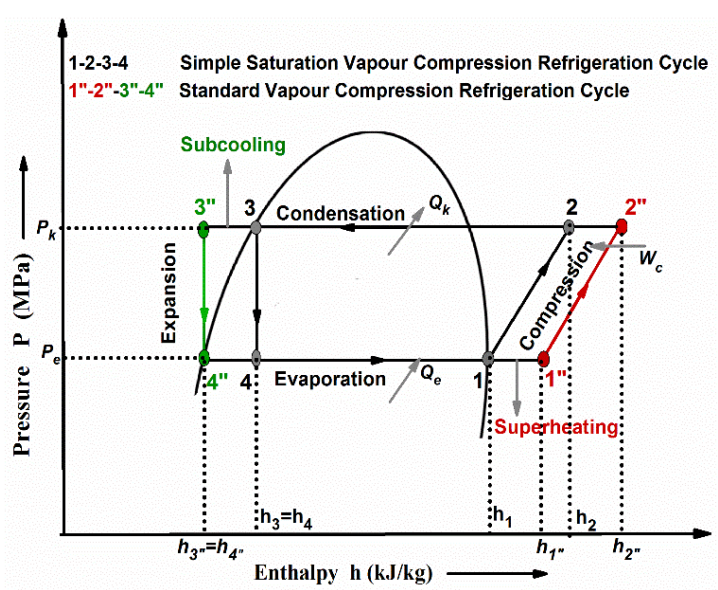

Figure 2. P-h chart of standard VCR cycle

The formulas used, while doing thermodynamic analysis of refrigerants were listed below.

Refrigerant mass flow rate is calculated as

$$
\dot{\mathrm{m}}=\frac{\mathrm{Q}_{\mathrm{c}}}{\mathrm{CE}}
$$

Cooling effect is calculated as

$$
\mathrm{CE}=\left(\mathrm{h}_{1^{\prime \prime}}-\mathrm{h}_{4 "}\right)
$$

Isentropic compressor work is calculated as

$$
\mathrm{W}_{\mathrm{c}}=\mathrm{h}_{2^{\prime \prime}}-\mathrm{h}_{1^{\prime \prime}}
$$

Coefficient of performance (COP) is computed as

$$
\mathrm{COP}=\mathrm{CE} / \mathrm{W}_{\mathrm{c}}
$$

Pressure ratio is calculated as

$$
\mathrm{P}_{\mathrm{r}}=\left(\frac{\mathrm{P}_{\mathrm{k}}}{\mathrm{P}_{\mathrm{e}}}\right)
$$

Power consumed per ton of refrigeration (PPTR) is calculated as

$$
\begin{gathered}
\text { PPTR }=\dot{\mathrm{m}} \mathrm{W}_{\mathrm{c}}=3.5\left(\frac{\mathrm{h}_{2^{\prime \prime}}-\mathrm{h}_{1^{\prime \prime}}}{\mathrm{h}_{1^{\prime \prime}}-\mathrm{h}_{4^{\prime \prime}}}\right) \\
\text { PPTR }=\dot{\mathrm{m}} \mathrm{W}_{\mathrm{c}}=3.5\left(\frac{\mathrm{W}_{\mathrm{c}}}{\mathrm{RE}}\right)=\left(\frac{3.5}{\mathrm{COP}}\right) \\
\dot{\mathrm{m}}=\frac{\mathrm{Q}_{\mathrm{c}}}{\mathrm{RE}}=\frac{3.5}{\mathrm{RE}}
\end{gathered}
$$

where, $\mathrm{Q}_{\mathrm{c}}=$ Capacity in terms of $\mathrm{TR}, 1 \mathrm{TR}=210 \mathrm{~kJ} / \mathrm{min}$ or 3.5 $\mathrm{kW}$.

Volumetric cooling (refrigeration) capacity is calculated as

$$
\mathrm{VCC}=\rho_{1^{\prime \prime}} \times \mathrm{CE}
$$

Compressor discharge temperature $\left(\mathrm{T}_{\text {disch }}\right)$ can be calculated as

$$
\begin{gathered}
\mathrm{S}_{2}=\mathrm{S}_{3}+\mathrm{C}_{\mathrm{p} 2} \times \ln \left(\frac{\mathrm{T}_{2^{\prime \prime}}}{\mathrm{T}_{3^{\prime \prime}}}\right)=\mathrm{S}_{1^{\prime \prime}} \\
\mathrm{S}_{1^{\prime \prime}}=\mathrm{S}_{1}+\mathrm{C}_{\mathrm{p} 1} \times \ln \left(\frac{\mathrm{T}_{1^{\prime \prime}}}{\mathrm{T}_{1}}\right)
\end{gathered}
$$


Results obtained from the thermodynamic analysis of refrigerant RE170 were compared with literature and they are shown in Table 10

Table 10. Comparison of results of thermodynamic analysis of refrigerant RE170 with literature results [22]

\begin{tabular}{ccccc}
\hline S.no & $\begin{array}{c}\text { Thermodynamic } \\
\text { Performance } \\
\text { parameters }\end{array}$ & $\begin{array}{c}\text { Literature } \\
\text { results for } \\
\text { RE170 }\end{array}$ & $\begin{array}{c}\text { Program } \\
\text { results } \\
\text { for } \\
\text { RE170 }\end{array}$ & $\begin{array}{c}\text { Deviation } \\
(\%)\end{array}$ \\
\hline 1 & $\mathrm{P}_{\mathrm{k}}(\mathrm{kPa})$ & 1143.10 & 1143.80 & -0.06 \\
2 & $\mathrm{P}_{\mathrm{e}}(\mathrm{kPa})$ & 185.10 & 185.03 & 0.03 \\
3 & $\mathrm{P}_{\mathrm{r}}$ & 6.18 & 6.18 & 0 \\
4 & $\mathrm{RE}(\mathrm{kJ} / \mathrm{kg})$ & 327.35 & 329.65 & -0.70 \\
5 & $\mathrm{~W}_{\mathrm{c}}(\mathrm{kJ} / \mathrm{kg})$ & 92.92 & 94.12 & 1.29 \\
6 & $\mathrm{COP}$ & 3.523 & 3.502 & 0.59 \\
7 & $\mathrm{PPTR}(\mathrm{kW} / \mathrm{TR})$ & 0.994 & 0.999 & -0.50 \\
8 & $\mathrm{VCC}\left(\mathrm{kJ} / \mathrm{m}^{3}\right)$ & 1297.50 & 1288.06 & 0.72 \\
9 & $\mathrm{~T}_{\mathrm{disch}}\left({ }^{\circ} \mathrm{C}\right)$ & 76.90 & 77.50 & -0.780 \\
\hline
\end{tabular}

From Table 10, it is noticed that the thermodynamic performance results obtained from present MATLAB program exhibits good agreement with literature results and the deviation of program results compared with literature results is within $1.5 \%$. Therefore, thermodynamic properties obtained from MHEOS which are used in the thermodynamic analysis of RE170 can be treated as reliable and also the MATLAB program which was developed in this study can be treated as reliable.

\section{RESULTS AND DISCUSSION}

\subsection{Global warming potential of refrigerant mixtures with RE170 as one of the blending components}

Figure 3 shows the global warming potential of various refrigerant mixtures. From Figure 3 and Table 3, it is observed that the GWP of ternary refrigerant mixtures such as TRM30 and TRM40 are lower when compared with R22, R407C and four investigated refrigerants, since TRM30 and TRM40 are blended with greater composition of very low GWP refrigerants such as R290, RE170 and R1270.

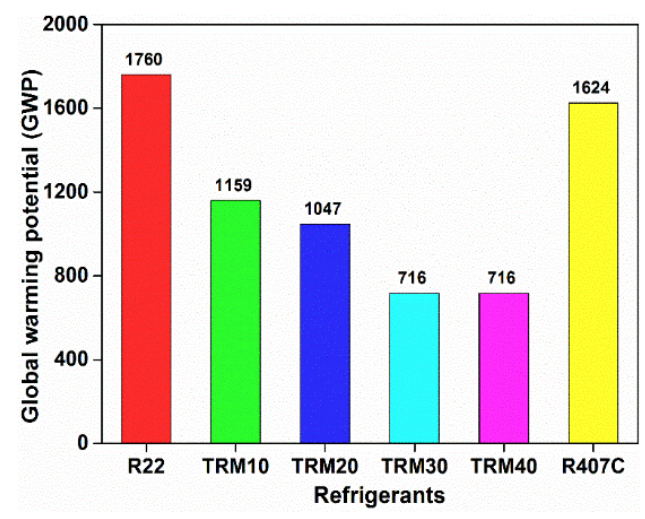

Figure 3. Global warming potential of refrigerant mixtures

\subsection{COP of refrigerant mixtures with RE170 as one of the blending components}

Figure 4 shows the COP of various refrigerant mixtures. From Figure 4 and Table 3, it is noticed that COP of ternary refrigerant mixture TRM30 (R134a/RE170/R1270 55/7.5/37.5 composition mass \%) was $5.35 \%$ higher than that of R22. And also refrigerant mixture TRM40 also has considerable increase in COP compared to R22, apart from refrigerant TRM30. From this thermodynamic performance results, it is evident that mixing the RE170 with other refrigerants (R134a, R290 and R1270) will enhances the performance of the system.

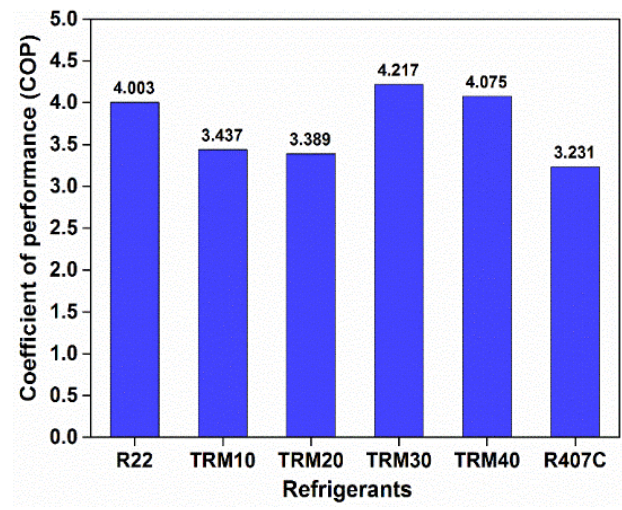

Figure 4. $\mathrm{COP}$ of refrigerant mixtures

\subsection{Computed $P_{\text {sat }}$ Vs REFPROP $P_{\text {sat }}$ for the refrigerant RE170}

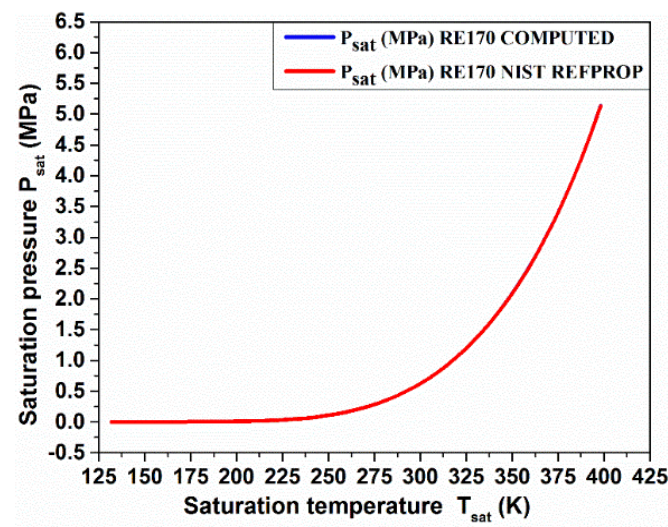

(a)

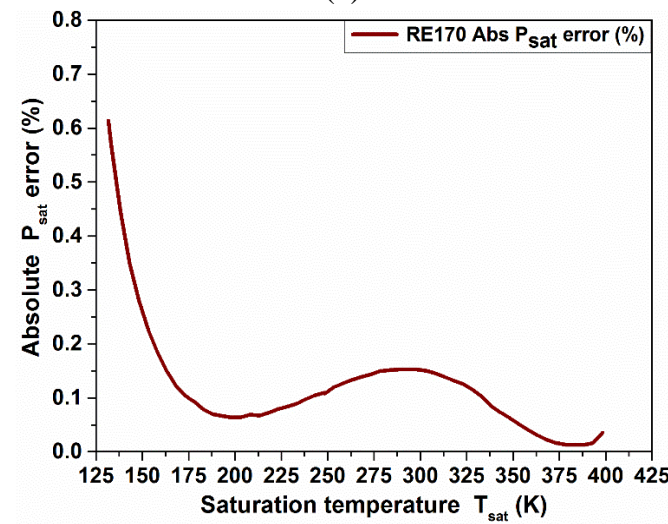

(b)

Figure 5. (a). Comparison of computed $\mathrm{P}_{\text {sat }}$ with REFPROP as a function of temperature; (b). Deviation of $\mathrm{P}_{\text {sat }}$ with REFPROP as a function of temperature

Wagner vapour pressure correlation is used to calculate the saturation pressure $\left(\mathrm{P}_{\text {sat }}\right)$ of the refrigerant RE170. From Figures 5(a) and 5(b), it is noticed that the computed saturation pressure values show good agreement with NIST REFPROP values and deviation obtained for the computed saturation 
pressure values of RE170 compared with REFPROP values is ranging from $0.114 \%$ to $0.150 \%$ for the given air conditioner operating conditions ( $280 \mathrm{~K}$ to $328 \mathrm{~K}$ ). Similarly deviation of saturation pressure of RE170 varies from $0.03 \%$ to $0.61 \%$ over the temperature range about $131 \mathrm{~K}$ to $363 \mathrm{~K}$. On the other hand, mean absolute deviation (MAD) of saturation pressure is $0.071 \%$ over wide temperature ranges from about $131.6 \mathrm{~K}$ to $398.15 \mathrm{~K}$ and wide pressure ranges from about $2.21 \times 10^{-5}$ bar to 51.3 bar.

\subsection{Computed of Vs REFPROP $\rho_{f}$ for the refrigerant RE170}

Reid method is used to compute the saturated liquid density $\left(\rho_{\mathrm{f}}\right)$ of the refrigerant RE170. From Figures 6(a) and 6(b), it is noticed that the computed liquid density values exhibit good agreement with NIST REFPROP data base and deviation obtained for the computed liquid density values of RE170 compared with REFPROP values is ranging from $0.045 \%$ to $0.179 \%$ for the given air conditioner operating conditions ( $280 \mathrm{~K}$ to $328 \mathrm{~K})$. Similarly deviation of liquid density of RE170 varies from $0.0088 \%$ to $0.19 \%$ over the temperature range about $131 \mathrm{~K}$ to $363 \mathrm{~K}$. On the other hand, mean absolute deviation (MAD) of liquid density is $0.253 \%$ over wide temperature ranges from about $131.6 \mathrm{~K}$ to $398.15 \mathrm{~K}$ and wide pressure ranges from about $2.21 \times 10^{-5}$ bar to 51.3 bar.

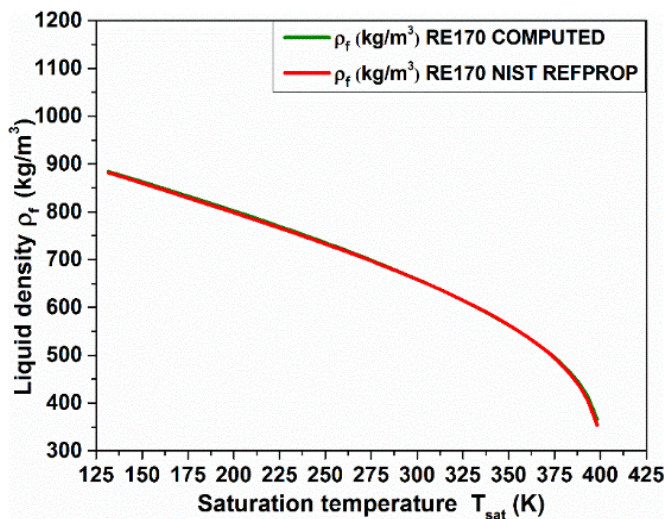

(a)

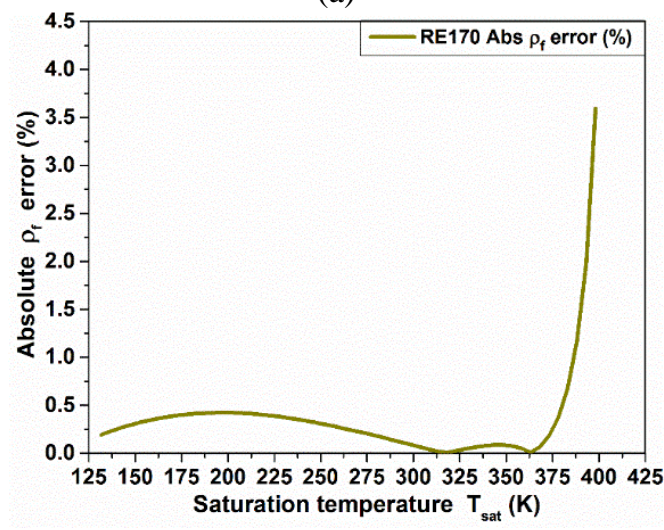

(b)

Figure 6. (a). Comparison of computed $\rho_{\mathrm{f}}$ with REFPROP as a function of temperature; (b). Deviation of $\rho_{\mathrm{f}}$ with REFPROP as a function of temperature

\subsection{Computed $V_{g}$ Vs REFPROP $V_{g}$ for the refrigerant RE170}

MHEOS is used to calculate the specific volume of vapour
$\left(\mathrm{V}_{\mathrm{g}}\right)$ of the given refrigerant RE170. From Figures 7(a) and 7(b), it is noticed that the computed vapour specific volume values show good agreement with NIST REFPROP data base and deviation obtained for the computed vapour specific volume values of RE170 compared with REFPROP values is ranging from $0.108 \%$ to $0.708 \%$ for the given air conditioner operating conditions ( $280 \mathrm{~K}$ to $328 \mathrm{~K}$ ). Similarly deviation of vapour specific volume of RE170 varies from $0.61 \%$ to $2.54 \%$ over the temperature range about $131 \mathrm{~K}$ to $363 \mathrm{~K}$. On the other hand, mean absolute deviation (MAD) of vapour specific volume is $1.49 \%$ over wide temperature ranges from about $131.6 \mathrm{~K}$ to $398.15 \mathrm{~K}$ and wide pressure ranges from about $2.21 \times 10^{-5}$ bar to $51.3 \mathrm{bar}$.

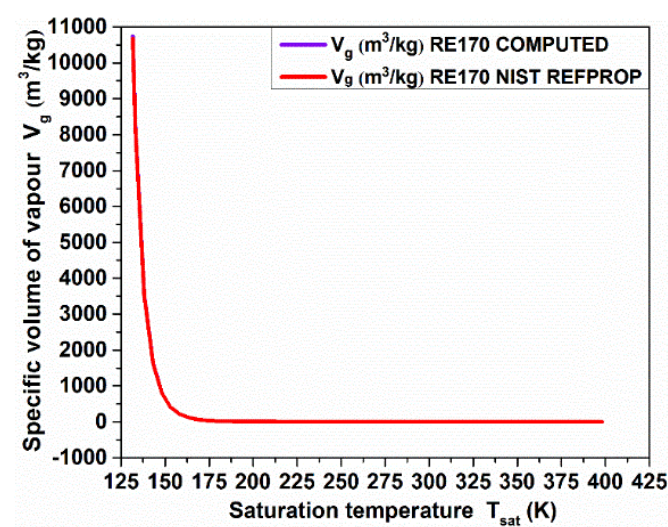

(a)

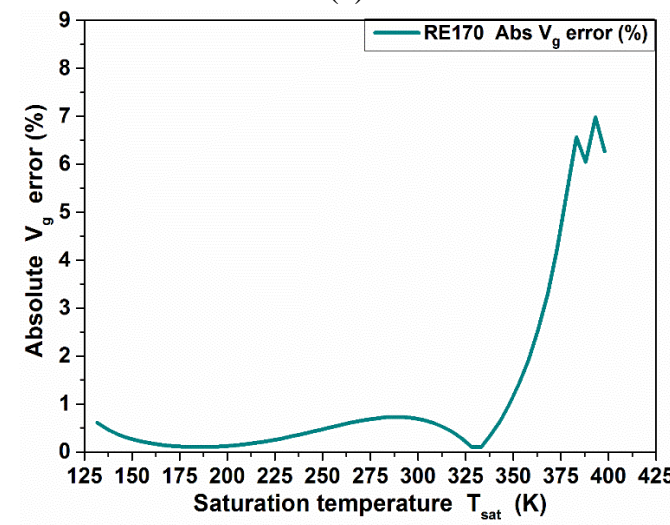

(b)

Figure 7 (a). Comparison of computed $\mathrm{V}_{\mathrm{g}}$ with REFPROP as a function of temperature; (b). Deviation of $V_{g}$ with REFPROP as a function of temperature

\subsection{Computed $h_{f}$ Vs REFPROP $h_{f}$ for the refrigerant RE170}

Enthalpy departure method and Clausius-Clapeyron equation is used to calculate the liquid enthalpy $\left(\mathrm{h}_{\mathrm{f}}\right)$ of the given refrigerant RE170. From Figures 8(a) and 8(b), it is noticed that the computed liquid enthalpy values exhibit good agreement with NIST REFPROP data base and deviation obtained for the computed liquid enthalpy values of RE170 compared with REFPROP values is ranging from $0.114 \%$ to $1.387 \%$ for the given air conditioner operating conditions ( $280 \mathrm{~K}$ to $328 \mathrm{~K})$. Similarly deviation of liquid enthalpy varies from $0.61 \%$ to $2.55 \%$ over the temperature range about 131 $\mathrm{K}$ to $363 \mathrm{~K}$. On the other hand, mean absolute deviation (MAD) of liquid enthalpy is $1.01 \%$ over wide temperature ranges from about $131.6 \mathrm{~K}$ to $398.15 \mathrm{~K}$ and wide pressure ranges from about $2.21 \times 10^{-5}$ bar to $51.3 \mathrm{bar}$. 


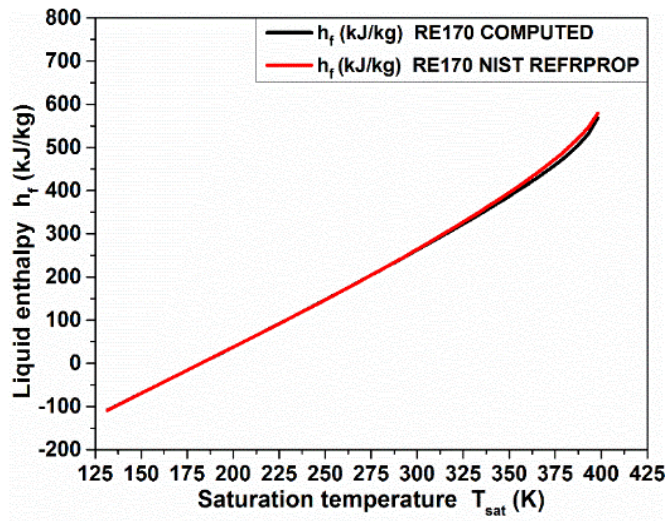

(a)

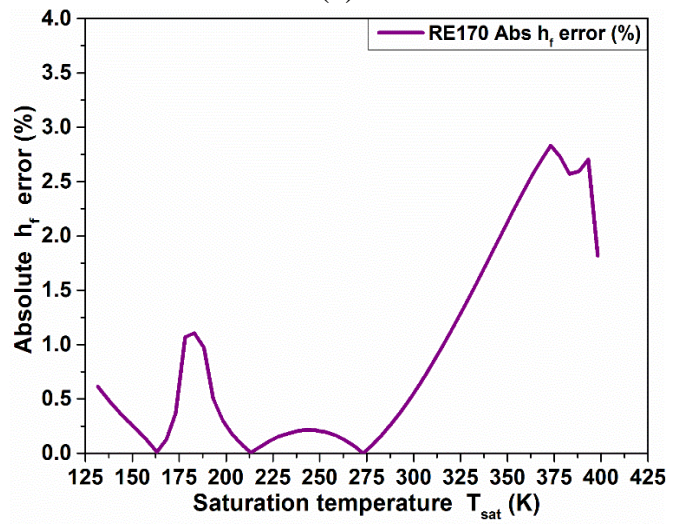

(b)

Figure 8. (a). Comparison of computed $\mathrm{h}_{\mathrm{f}}$ with REFPROP as a function of temperature; (b). Deviation of $h_{f}$ with REFPROP as a function of temperature

\subsection{Computed $h_{g}$ Vs REFPROP $h_{g}$ for the refrigerant RE170}

Enthalpy departure method and Clausius-Clapeyron equation is used to compute the vapour enthalpy $\left(\mathrm{h}_{\mathrm{g}}\right)$ of the given refrigerant RE170. From Figures 9(a) and 9(b), it is noticed that the computed vapour enthalpy values show good agreement with NIST REFPROP data base and deviation obtained for the computed vapour enthalpy values of RE170 compared with REFPROP values is varies from $0.372 \%$ to $0.627 \%$ for the given air conditioner operating conditions $(280 \mathrm{~K}$ to $328 \mathrm{~K})$. Similarly deviation of vapour enthalpy varies from $0.067 \%$ to $0.283 \%$ over the temperature range about $131 \mathrm{~K}$ to $363 \mathrm{~K}$. On the other hand, mean absolute deviation (MAD) of vapour enthalpy is $0.319 \%$ over wide temperature ranges from about $131.6 \mathrm{~K}$ to $398.15 \mathrm{~K}$ and wide pressure ranges from about $2.21 \times 10^{-5}$ bar to $51.3 \mathrm{bar}$.

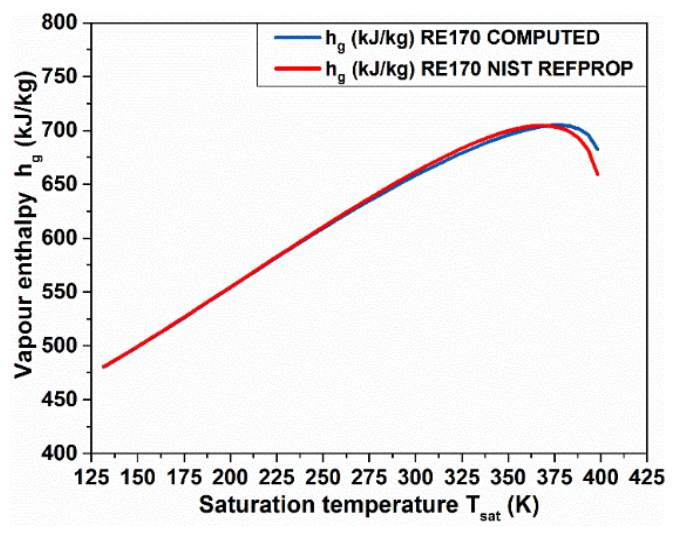

(a)

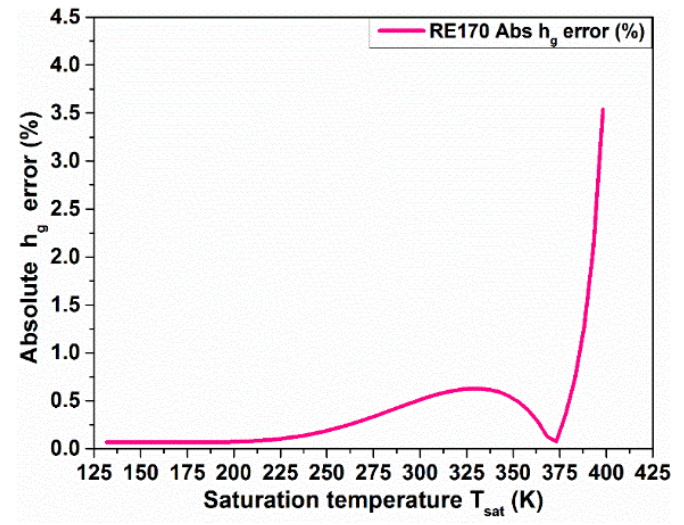

(b)

Figure 9. (a). Comparison of computed $h_{g}$ with REFPROP as a function of temperature; (b). Deviation of $h_{g}$ with REFPROP as a function of temperature

\subsection{Computed Sf Vs REFPROP Sf for the refrigerant RE170}

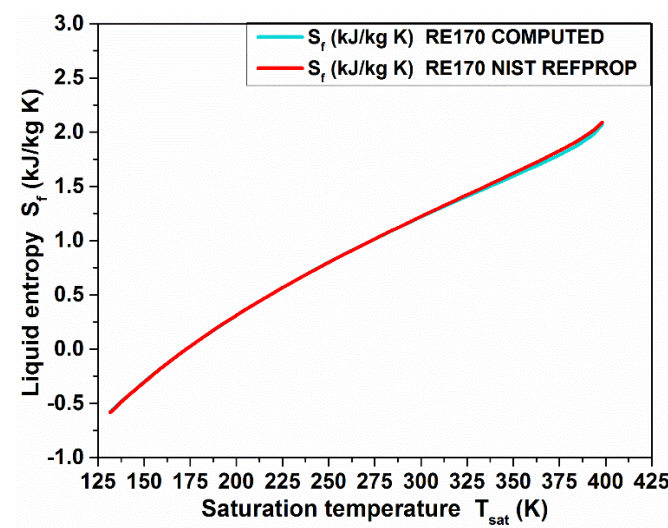

(a)

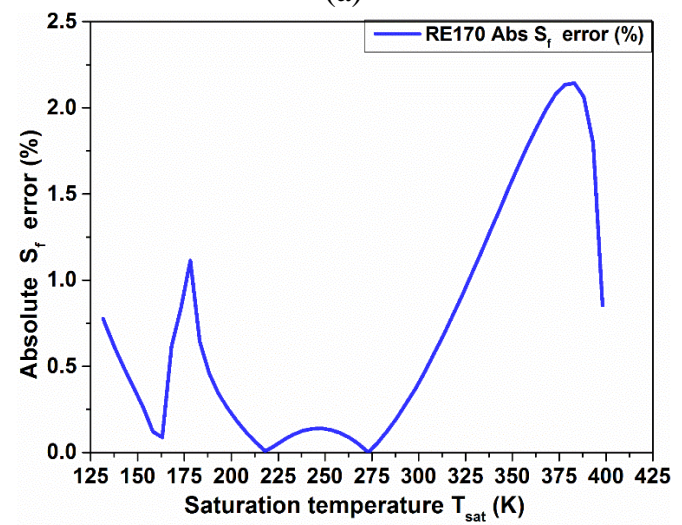

(b)

Figure 10. (a). Comparison of computed $S_{f}$ with REFPROP as a function of temperature; (b). Deviation of $\mathrm{S}_{\mathrm{f}}$ with REFPROP as a function of temperature

The departure method and Clasius-Clayperon equation is used to calculate the liquid entropy $\left(\mathrm{S}_{\mathrm{f}}\right)$ of the given refrigerant RE170. From Figures 10(a) and 10(b), it is noticed that the computed liquid entropy values exhibit good agreement with NIST REFPROP data base and deviation obtained for the computed liquid entropy values of RE170 compared with REFPROP values is varies from $0.082 \%$ to $1.032 \%$ for the given air conditioner operating conditions ( $280 \mathrm{~K}$ to $328 \mathrm{~K}$ ). Similarly deviation of liquid entropy varies from $0.775 \%$ to 
$1.889 \%$ over the temperature range about $131 \mathrm{~K}$ to $363 \mathrm{~K}$. On the other hand, mean absolute deviation (MAD) of liquid entropy is $1.055 \%$ over wide temperature ranges from about 131.6 $\mathrm{K}$ to $398.15 \mathrm{~K}$ and wide pressure ranges from about $2.21 \times 10^{-5}$ bar to 51.3 bar.

\subsection{Computed $S_{g}$ Vs REFPROP $S_{g}$ for the refrigerant RE170}

The departure method and Clasius-Clayperon equation is used to calculate the vapour entropy $\left(S_{\mathrm{g}}\right)$ of the given refrigerant RE170. From Figures 11(a) and 11(b), it is noticed that the computed vapour entropy values show good agreement with NIST REFPROP data base and deviation obtained for the computed vapour entropy values of RE170 compared with REFPROP values is varies from $0.329 \%$ to $0.550 \%$ for the given air conditioner operating conditions ( $280 \mathrm{~K}$ to $328 \mathrm{~K})$. Similarly deviation of vapour entropy varies from $0.078 \%$ to $0.305 \%$ over the temperature range about 131 $\mathrm{K}$ to $363 \mathrm{~K}$. On the other hand, mean absolute deviation (MAD) of vapour entropy is $0.262 \%$ over wide temperature ranges from about $131.6 \mathrm{~K}$ to $398.15 \mathrm{~K}$ and wide pressure ranges from about $2.21 \times 10^{-5}$ bar to 51.3 bar.

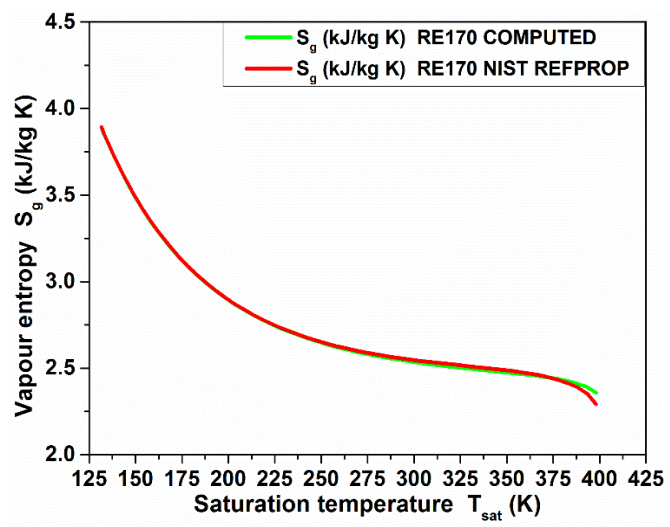

(a)

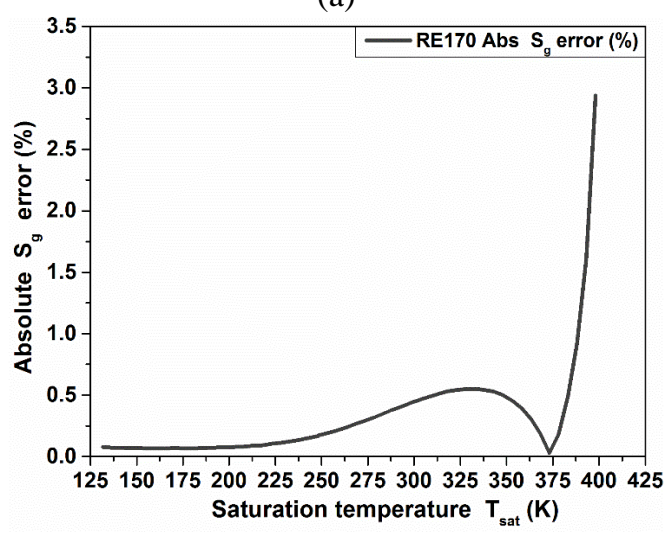

(b)

Figure 11. (a). Comparison of computed $S_{g}$ with REFPROP as a function of temperature; (b). Deviation of $S_{g}$ with REFPROP as a function of temperature

\section{CONCLUSIONS}

In this work an attempt was made to compute ecological properties, flammability properties of RE170 and also to establish the thermodynamic properties of an ecofriendly refrigerant RE170 (Dimethylether) using MHEOS over the wide temperature range about $131.6 \mathrm{~K}$ to $398.15 \mathrm{~K}$ and pressure up to 51.3 bar. The conclusions drawn from this investigation are presented below.

- Ecological properties exhibited that refrigerant RE170 has zero ODP and very low GWP (equal to one) compared to other four studied refrigerant mixtures.

- Flammability study exhibited that refrigerant RE170 was classified into highly flammable group (ASHRAE A3) and hence safety precautions must be followed while using RE170. And also refrigerant RE170 has UFL of $25.60 \mathrm{vol} \%$, LFL of $3.34 \mathrm{vol} \%$ and RF number of $51.05 \mathrm{~kJ} / \mathrm{g}$, respectively.

- In this study, thermodynamic properties generated were validated against NIST REFPROP database. Martin-Hou equation of state was found to be an appropriate equation of state in the operating temperature region (280-328 K) of residential air conditioner, since the deviation of all the computed and developed properties $\left(\mathrm{P}_{\mathrm{sat}}, \rho_{\mathrm{f}}, \mathrm{V}_{\mathrm{g}}, \mathrm{h}_{\mathrm{f}}, \mathrm{h}_{\mathrm{g}}, \mathrm{S}_{\mathrm{f}}\right.$ and $\mathrm{S}_{\mathrm{g}}$ ) were within $1 \%$ when compared with NIST REFPROP database.

- Similarly deviation of computed thermodynamic properties of refrigerant RE170 for the temperature range (131 $\mathrm{K}$ to $363 \mathrm{~K}$ ) was within $2.5 \%$. This study exhibited that there was considerable increase in deviation of properties as the computation approaches to critical point or critical region.

- $\quad$ Also in this study, mean absolute deviation (MAD) of all the computed thermodynamic properties of RE170 was found. MAD of saturation pressure and liquid density was $0.071 \%$ and $0.25 \%$, respectively over the entire temperature range about $131.6 \mathrm{~K}$ to $398.15 \mathrm{~K}$ and pressure up to $51.3 \mathrm{bar}$.

- MAD of saturated vapour phase of both enthalpy and entropy was $0.31 \%$ and $0.26 \%$, whereas MAD of saturated liquid phase enthalpy and entropy was 1.01 and $1.05 \%$ over wide temperature about $131.6 \mathrm{~K}$ to $398.15 \mathrm{~K}$ and pressure up to 51.3 bar.

- MAD of vapour specific volume of RE170 was $1.49 \%$ over the wide temperature range about $131.6 \mathrm{~K}$ to $398.15 \mathrm{~K}$ and pressure up to $51.3 \mathrm{bar}$.

- However, mean absolute deviation (MAD) of all the properties was within $1.05 \%$ as the temperature approaches near to critical region. Hence the developed thermodynamic properties of refrigerant RE170 by using MHEOS were considered as reliable and these properties would be useful and applicable for computing and analyzing the thermodynamic performance characteristics of VCR system.

- The present study revealed that blending the refrigerant RE170 as one of the mixing components with other refrigerants not only enhances the performance of refrigerant mixture, but it also redues the GWP of refrigerant mixture.

- The Martin-Hou equation of state (MHEOS) can be conveniently used for further future research work on development of properties of any given pure refrigerants and also experimental PvT properties of any pure substance can be validated with the properties obtained from MHEOS.

- Flammability correlations used in the present study provides the essential information to the researchers to classify the any given new refrigerants into various safety categories.

\section{REFERENCES}

[1] United Nations Environmental Programme. (1987). Montreal Protocol on substances that deplete the ozone layer Final act, New York, United Nations. 
[2] Powell, R.L. (2002). CFC Phase out: Have we met the challenge. Journal of Fluorine Chemistry, 114(2): $237-$ 250. https://doi.org/10.1016/S0022-1139(02)00030-1

[3] Mohanraj, M., Jayaraj, S., Muraleedharan, C. (2009). Environment friendly alternatives to halogenated Refrigerants-A review. International Journal of Greenhouse Gas Control, 3(1): 108-119. https://doi.org/10.1016/j.ijggc.2008.07.003

[4] Barret, M., Candau, Y. (1992). Thermodynamic properties computation of two possible substitute refrigerants: R143a (1,1,1-trifluoroethane) and R125 (Pentafluoroethane). International Refrigeration and Air Conditioning Conference, Purdue, USA, pp. 433-442.

[5] De Monte, F. (2002a). Calculation of thermodynamic properties of R407C and R410A by the Martin-Hou equation of state - part I: Theoretical development. International Journal of Refrigeration, 25(3): 306-313. https://doi.org/10.1016/S0140-7007(01)00028-7

[6] De Monte, F. (2002b). Calculation of thermodynamic properties of R407C and R410A by the Martin-Hou equation of state - part II: Technical interpretation. International Journal of Refrigeration, 25(3): 314-329. https://doi.org/10.1016/S0140-7007(01)00029-9

[7] Agrawal, A., Cornelio, A.A., Limperich, D. (2012). Investigation of cubic EOS models for HFO-1234yf refrigerant used in automotive application. International Refrigeration and Air Conditioning Conference, Purdue, USA, pp. 1-10.

[8] Moghadassi, A.R., Nikkholgh, M.R., Parvizian, F., Hosseini, S.M. (2010). Estimation of thermophysical properties of dimethyl ether as a commercial refrigerant based on artificial neural networks. Expert Systems with Applications, $37(2)$ : 7755-7761. https://doi.org/10.1016/j.eswa.2010.04.065

[9] Kim, N.H. (2016). Application of the natural refrigerant mixture R-290/DME to a soft ice cream refrigerator. International Journal of Air-Conditioning and Refrigeration, 24(4): 1650027. https://doi.org/10.1142/S2010132516500279

[10] Miyara, A., Onaka, Y., Koyama, S. (2012). Ways of next generation refrigerants and heat pump/refrigeration systems. International Journal of Air-Conditioning and Refrigeration, 20(1): 1130002. https://doi.org/10.1142/S2010132511300023

[11] Brown, J.S., Fedele, L., Nicola, G.D. (2015). Compressed liquid density and vapor phase PvT measurements of cis-1,2,3,3,3-Pentafluoroprop-1-ene (R1225ye(Z)). Journal of Chemical Engineering \& Data, 60(11): 3333-3340. https://doi.org/10.1021/acs.jced.5b00562

[12] Nicola, G.D., Brown, J.S., Fedele, L., Securo, M., Bobbo, S., Zillo, C. (2013). Subcooled liquid density measurements and PvT measurements in the vapor phase for 3,3,3-trifluoroprop-1-ene (R1243zf). International Journal of Refrigeration, 36(8): 2209-215. https://doi.org/10.1016/j.ijrefrig.2013.08.004

[13] Brown, J.S., Nicola, G.D., Zillo, C., Fedele, L., Bobbo, S., Polonara, F. (2012). Subcooled liquid density measurements and PvT measurements in the vapor phase for trans-1,3,3,3-Tetrafluoroprop-1-ene (R1234ze(E)). Journal of Chemical \& Engineering Data, 57(12): 37103720. https://doi.org/10.1021/je300945r

[14] Nicolla, C.D., Nicolla, G.D., Paceti, M., Polonara, F., Santori, G. (2010). P-V-T Behavior of 2,3,3,3- tetrafluoroprop-1-ene (HFO-1234yf) in the vapor phase from (243 to 373) K. Journal of Chemical and Engineering Data, 55(9): 3302-3306. https://doi.org/10.1021/je100102q

[15] Dong, L., Zhang, Y., Li, S., Wei, S., Zhang, J., Qi, Y. (2012). An empirical equation to directly calculate parameter B4 of the Martin-Hou equation of state. Chemical Engineering Communication, 199(5): 577-586. https://doi.org/10.1080/00986445.2011.599899

[16] ASHRAE. (2017). ASHRAE handbook- fundamentals American Society of Heating, Refrigerating and AirConditioning Engineers, Atlanta, USA.

[17] Lemmon, E.W., Huber, M.L., McLinden, M.O. (2013). NIST Reference Fluid Thermodynamic and Transport Properties-REFPROP, NIST Standard Reference Database 23-Version 9.1.

[18] https://www.esrl.noaa.gov/csd/assessments/ozone/2006/, accessed on 18 December 2018.

[19] https://www.esrl.noaa.gov/csd/assessments/ozone/2006/ chapters/chapter8.pdf, accessed on 18 December 2018.

[20] Good, D.A., Francisco, J.S., Jain, A.K., Wuebbles, D.J. (1998). Lifetimes and global warming potentials for dimethyl ether and for fiuorinated ethers: $\mathrm{CH}_{3} \mathrm{OCF}_{3}$ (E143a), $\mathrm{CHF}_{2} \mathrm{OCHF}_{2}$ (E134), $\mathrm{CHF}_{2} \mathrm{OCF}_{3}$ (E125). Journal of Geophysical Research, 103(D21): 2818128186. https://doi.org/10.1029/98JD01880

[21] Hodnebrog, O., Etminan, M., Fuglestvedt, J.S., Marston, G., Myhre, G., Nielsen, C.J., Shine, K.P., Wallington, T.J. (2013). Global warming potentials and radiative efficiencies of halocarbons and related compounds: A comprehensive review. Reviews of Geophysics, 51(2): 300-378. https://doi.org/10.1002/rog.20013

[22] Baskaran, A., Koshy Mathews, P. (2012). A Performance comparison of vapour compression refrigeration system using Eco friendly refrigerants of low global warming potential. International Journal of Scientific and Research Publications, 2(9): 1-8.

[23] Shaik, S.V., Babu, T.P.A. (2017). Theoretical computation of sustainable energy efficient R22 alternatives for residential air conditioners. Energy Procedia, 138: 710-716. https://doi.org/10.1016/j.egypro.2017.10.205

[24] Pintar, A.J. (1999). Predicting lower and upper flammability limits. International Conference on Fire Safety, Product Safety Corporation, Sissonville, p. 28.

[25] Hilado, C.J. (1975). A method for estimating limits of flammability. Journal of Fire and Flammability, 6: 130139.

[26] Hristova, M., Tchaoushev, S. (2006). Calculation of flash points and flammability limits of substances and mixtures. Journal of the University of Chemical Technology and Metallurgy, 41(3): 291-296.

[27] Kondo, S., Takahashi, A., Tokuhashi, K., Sekiya, A. (2002). RF number as a new index for assessing combustion hazard of flammable gases. Journal of Hazardous Materials, 93(3): 259-267. https://doi.org/10.1016/S0304-3894(02)00117-6

[28] ANSI/ASHRAE for Designation and Safety Classification of Refrigerants (2007). ANSI/ASHRAE Standard 34.

[29] Arora, C.P. (2009). Refrigeration and Air conditioning. Tata McGraw-Hill, New Delhi.

[30] Forero, G.L.A., Velásquez, J.J.A. (2011). Wagner liquidvapour pressure equation constants from a simple 
methodology. The Journal of Chemical Thermodynamics, 43(8): 1235-1251. https://doi.org/10.1016/j.jct.2011.03.011

[31] Reid, R.C., Prausnitz, J.M., Sherwood, T.K. (1977). The Roperties of Gases and Liquids. McGraw-Hill, New York.

[32] Nasrifar, K., Moshfeghian, M. (1999). Evaluation of saturated liquid density prediction methods for pure refrigerants. Fluid Phase Equilibria, 158: 437-445. https://doi.org/10.1016/S0378-3812(99)00068-0

[33] Poling, B.E., Prausnitz, J.M., O’Connell, J.P. (2001). The Properties of Gases and Liquids. McGraw-Hill, New York.

[34] Martin, J.J., Hou, Y.C. (1955). Development of an equation of state for gases. AIChE Journal, 1(2): 142-151. https://doi.org/10.1002/aic.690010203

\section{NOMENCLATURE}

BP Boiling point, ${ }^{\circ} \mathrm{C}$

CE Cooling effect, $\mathrm{kJ} / \mathrm{kg}$

COP Coefficient of performance, Dimensionless

$\mathrm{C}_{\mathrm{p} 0} \quad$ Ideal gas heat capacity, $\mathrm{J} / \mathrm{mol} \mathrm{K}$

HOC Enthalpy of combustion, $\mathrm{kJ} / \mathrm{mol}$

$\mathrm{h} \quad$ Enthalpy, $\mathrm{kJ} / \mathrm{kg}$

$\mathrm{h}_{\mathrm{f}} \quad$ Liquid enthalpy, $\mathrm{kJ} / \mathrm{kg}$

$\mathrm{h}_{\mathrm{fg}} \quad$ Enthalpy of vapourization, $\mathrm{kJ} / \mathrm{kg}$

$\mathrm{h}_{\mathrm{g}} \quad$ Vapour enthalpy, $\mathrm{kJ} / \mathrm{kg}$

LFL Lower flammability limit, vol\%

MW Molecular weight, $\mathrm{kg} / \mathrm{kmol}$

$\mathrm{P} \quad$ Pressure, $\mathrm{MPa}$

$\mathrm{P}_{\mathrm{c}} \quad$ Critical pressure, $\mathrm{Mpa}$

$\mathrm{P}_{\text {sat }} \quad$ Saturation pressure, Mpa

PPTR Power consumed per ton of refrigeration, $\mathrm{kW} / \mathrm{TR}$

$\mathrm{Q}_{\mathrm{c}} \quad$ Refrigeration capacity, $\mathrm{kW}$

$\mathrm{R} \quad$ Universal gas constant, $\mathrm{J} / \mathrm{mol} \mathrm{K}$

$\mathrm{S}_{\mathrm{f}} \quad$ Liquid entropy, $\mathrm{kJ} / \mathrm{kg} \mathrm{K}$

$\mathrm{S}_{\mathrm{fg}} \quad$ Entropy of vapourization, $\mathrm{kJ} / \mathrm{kg} \mathrm{K}$

$\mathrm{S}_{\mathrm{g}} \quad$ Vapour entropy, $\mathrm{kJ} / \mathrm{kg} \mathrm{K}$

$\mathrm{T}$ Temperature, $\mathrm{K}$

$\mathrm{T}_{\mathrm{c}} \quad$ Critical temperature, $\mathrm{K}$

$\mathrm{T}_{\text {disch }} \quad$ Compressor discharge temperature, ${ }^{\circ} \mathrm{C}$

$\mathrm{T}_{\mathrm{e}} \quad$ Evaporating temperature, ${ }^{\circ} \mathrm{C}$

$\mathrm{T}_{\mathrm{k}} \quad$ Condensing temperature, ${ }^{\circ} \mathrm{C}$

TR Ton of refrigeration, $\mathrm{kW}$

$\mathrm{T}_{\text {sat }} \quad$ Saturation temperature, $\mathrm{K}$
$U \quad$ Internal energy, $\mathrm{kJ} / \mathrm{kg}$

UFL Upper flammability, vol\%

VCC Volumetric cooling capacity, $\mathrm{kJ} / \mathrm{m}^{3}$

$\mathrm{V}_{\mathrm{g}} \quad$ Vapour specific volume, $\mathrm{m}^{3} / \mathrm{kg}$

$\mathrm{V}_{\mathrm{f}} \quad$ Liquid volume, $\mathrm{m}^{3} / \mathrm{kg}$

$\mathrm{W}_{\mathrm{c}} \quad$ Specific work of compressor, $\mathrm{kJ} / \mathrm{kg}$

$\rho \quad$ Density, $\mathrm{kg} / \mathrm{m}^{3}$

$\rho_{\mathrm{c}} \quad$ Critical density, $\mathrm{kg} / \mathrm{m}^{3}$

$\rho_{\mathrm{f}} \quad$ Liquid density, $\mathrm{kg} / \mathrm{m}^{3}$

$\omega \quad$ Accentric factor, Dimensionless

\section{Greek symbols}

$\rho \quad$ Density, $\mathrm{kg} / \mathrm{m}^{3}$

$\rho_{\mathrm{c}} \quad$ Critical density, $\mathrm{kg} / \mathrm{m}^{3}$

$\omega \quad$ Accentric factor, Dimensionless

$\Delta T_{\text {Sub }} \quad$ Degree of subcooling, ${ }^{\circ} \mathrm{C}$

$\Delta T_{\text {Sup }} \quad$ Degree of superheating, ${ }^{\circ} \mathrm{C}$

\section{Subscripts}

c Critical

f Liquid phase

g Vapour phase

Sub Subcooling

Sup Superheating

\section{Abbreviations}

AHRI Air-Conditioning, Heating, and Refrigeration Institute

ASHRAE American Society of Heating, Refrigerating and Air-Conditioning Engineers

BP Boiling point

CE Cooling effect

COP Coefficient of performance

GWP Global warming potential

HCFCs Hydrochlorofluorocarbons

HFCs Hydrofluorocarbons

HOC Enthalpy of combustion

MHEOS Martin-Hou equation of state

ODP Ozone depleting potential

PPTR Power required per ton of refrigeration

RF Refrigerant flammability

VCR Vapour compression refrigeration 